\title{
Effect of an Integrated Resistance Program Based Weightlifting Exercises on Improving Physical Performance of Young Table Elite's Tennis Players
}

\author{
Kaabi Sofiene ${ }^{1,2}$, Souhail Hermassi'2,3, Kaabi Safa4 ${ }^{4}$, Phillipe Passelergue ${ }^{1}$ \\ ${ }^{1}$ Laboratoire Mouvement, Equilibre, Performance, Santé (MEPS), EA 4445, Département (STAPS), Université de Pau et des Pays de \\ l'Adour, Tarbes, France \\ ${ }^{2}$ Research Laboratory "Sports Performance Optimization” National Center of Medicine and Science in Sports (CNMSS), Tunis, Tunisia \\ ${ }^{3}$ High Institute of Sport and Physical Education, Ksar-Saï, Manouba University, Manouba, Tunisia \\ ${ }^{4}$ High Institute of Sport and Physical Education, Gafsa, Gafsa University, Gafsa, Tunisia \\ Email: haltero99@hotmail.fr
}

How to cite this paper: Sofiene, K., Hermassi, S., Safa, K., \& Passelergue, P. (2016). Effect of an Integrated Resistance Program Based Weightlifting Exercises on Improving Physical Performance of Young Table Elite's Tennis Players. Advances in Physical Education, 6, 364-377.

http://dx.doi.org/10.4236/ape.2016.64037

Received: September 8, 2016

Accepted: November 3, 2016

Published: November 7, 2016

Copyright $\odot 2016$ by authors and Scientific Research Publishing Inc. This work is licensed under the Creative Commons Attribution International License (CC BY 4.0).

http://creativecommons.org/licenses/by/4.0/ (c) (i) Open Access

\begin{abstract}
The purpose of our study was to find out the results of a training program based on the Olympic exercises (weightlifting), on the performance of strength and power in high-level table tennis players. Thirty elite table tennis players (age $18.05 \pm 1.04$ years) were randomly divided into a control group (CG; $n=15)$ and an experimental group (WRTG; $n=15$ ). The last group followed a weightlifting training program for 6 weeks with 3 sessions per week during the competitive period. As for the control group, he pursued classical table tennis training. Before and after the 6-week training program, all players have conducted tests on sprint distance of $5 \mathrm{~m}$, the vertical jump (squat jump and countermovement jump), strength hand grip, throwing medicine Ball, the 1-RM bench press and 1-RM 1/2 squat test. A slight raise in the 1-RM maximum strength of upper and lower limbs (respectively $p<0.05 ; 7.87 \mathrm{~kg}$ or $8.29 \%$ and $p<0.04 ;+10.7$ kilograms or $17.75 \%$ ) for the WRTG compared to CG this evolution was followed by an obvious changes in strength hand grip at the EG compared to CG ( $p<0.01 ; 4.6 \mathrm{~kg}$ or $13.54 \%$ of development). According to the outcomes of our study, we can declare that a strength training program during three sessions per week during the competitive period, can lead to a developed strength in the maximum lower limb, the and vertical jump among the elite table tennis players. The identification such as results could be considered a reliable device for coaches and technicians concerned to develop the performance of their table tennis players.
\end{abstract}

\section{Keywords}

Physical Load, Weightlifting, Progressive Overload, Table Tennis, Performance 


\section{Introduction}

In modern sports, the developing of specific physical aspects has become fundamental to reach optimal performance. Besides, it's crucial to adopt transformations in different factors of training, for instance intensity of the load and the number of repetitions, the volume of the series leads to promote the motor qualities of the athlete (Kraemer \& Ratamess, 2004).

The modern physical preparation strategies are mainly based on the improvement of neuromuscular qualities and seem to be the product of this scientific development in modern sport (Kraemer et al., 2002).

In table tennis, the development of training should be related to the energy needs required by the competition. So, it is necessary to know the physical requirements and the main pillars of the motor activity, capacity and the table tennis players training mechanisms maintained (Yáñez Sepúlveda et al., 2015).

In fact, the table tennis is considered as an individual sport and it has a recurrent and explosive nature mixed with a very short and intense action creates the basic item of performance in this practice (Zagatto et al., 2008; Fédération International de Tennis de Table; Munivrana et al., 2015).

Actually, the maximum force, execution speed, acceleration and the powers of the lower limbs build are the main qualities of tennis table which first, allow the tennis table players to support the strong muscle contractions, then, to be more potent in many actions of ball exchanges with the adversary (Zagatto et al., 2008; Yáñez Sepúlveda et al., 2015).

Among the mechanisms of developing the neuromuscular performance in Table Tennis, we can mention the resistance training (i.e., muscle building) which is a physical progress to adjust biological properties of nerve and muscle tissue (Sarabia et al., 2015).

According to the specific literature in this realm, the sort of strength training (i.e., the charge used, intensity and volume) is considered as one of the basic forms of development of explosive and muscle power (Toriola et al., 2004).

The evolution of the load resistance training (i.e., maximum force) associates a continuous progress of an exclusive variable until the purpose is reached. The category and/or strength training exemplary in terms of the load (i.e., intensity) followed is usually considered as one of the basic components in the development of muscle strength.

Yet, two training procedures that oppose one of these mechanism, is to use heavy loads (i.e., $80 \%-90 \%$ of $1-\mathrm{RM}$ ) to boost the recruitment of the fast fibres on the other mechanisms is to train at speeds that approximate the actual speed of the performance of the athlete ( $50 \%-60 \%$ of $1-\mathrm{RM})$ and using moderate loads.

Besides, muscle strength training with quasi-moderate loads (i.e., 50\% - 60\% of 1-RM) develops the rapid stimulation of dynamic movement (McBride et al., 1999; Crewther et al., 2005). Moreover, the analysis of the literature proclaims that strength training weight training with heavy loads remains largely disputed especially with racket sports (Kraemer et al., 2002; Crewther et al., 2005; Crewther et al., 2011). Physiological adaptations are derived from the muscular performance advancement 
and considered as a dynamics strengthresistance programs that would also be linked to neural and mechanical adaptation of muscles (West et al., 2011; Cormie et al., 2011).

Furthermore, the benefits of dynamic strength would be associated to awakening of the fact of specific strength training speed (Kraemer et al., 2002; Crewther et al., 2011) apparently caused by the contractions of opponent muscles to those stretched (West et al., 2013).

Thus, several scientific reports have revealed that the employment of specific strength training exercises can be a trust worthy approach of training to develop a specific performance in table tennis (Kraemer et al., 2002; Kraemer et al., 2009).

Besides, the survey of fitness program containing table tennis heavy loads (i.e., $80 \%$ of 1-RM) and their outcomes on the explosive performance has become the subject of that very few previous studies and has produced mixed results (Sarabia et al., 2015).

Then, it would be very important to compare a series of an integrated stimulation of fitness program during the season (different volumes and intensity) based on the Olympic exercises (weightlifting), able of bringing motor benefits on a definite time table tennis player.

Taking into consideration what has been developed above, we sat as targets first, studying the consequences during the sports season with a training program of the dynamic force (i.e., exercise weightlifting) on muscle performance and lower limb superiors. Besides, optimizing the specific motor skills in elite's table tennis player leads us to the specific objectives below.

Examining and comparing the impacts of a weight training program for lower and upper limbs 6 weeks to three weekly sessions on the performance of maximum strength, vertical jump, speed running performance and agility among table tennis player's elites.

\section{Methods}

\subsection{Subjects}

The objective of this study was to evaluate the training effects of Olympic weightlifting exercises with table tennis elite players on functional and physiological measures. Thirty Tunisian elite table tennis player. male (age $18.06 \pm 1.18$ years, height $160 \mathrm{~cm} \pm$ 0.06 , body masses $63.63 \pm 6.96 \mathrm{~kg}$, a body fat percentage equal to $14.92 \pm 2.04$ and body mass indicator of about $24.79 \pm 1.73$ ) managing in three regional selections were selected for carrying out the study with 3 years training experience. All subjects are related to the same socio-economic and routinely train at the same daily training schedules from $16 \mathrm{~h}$ to $18 \mathrm{~h}$ in the training room of the national team (youth city of El Menzah, Tunis) (Table 1).

In this analysis no athletes were involved in additional training of strength or specific packaging 6 weekly trainings including 3 technical sessions and 3 training sessions during the competition period during the months of July and August 2015. All subjects signed a letter containing information on the study and a request for consent to participate in this study. 
Table 1. Anthropometric characteristic of the two groups (mean $\pm \mathrm{SD}$ ).

\begin{tabular}{|c|c|c|c|c|c|}
\hline $\begin{array}{l}\text { Parameters } \\
\text { Groups }\end{array}$ & Age (years) & Height $(\mathrm{cm})$ & Weight $(\mathrm{kg})$ & $\%$ M.G & Body fat \\
\hline CG & $18.08 \pm 1.32$ & $159.53 \pm 5.55$ & $62.90 \pm 5.69$ & $15.58 \pm 1.46$ & $24.70 \pm 1.57$ \\
\hline WRTG & $18.05 \pm 1.04$ & $160.60 \pm 7.16$ & $64.36 \pm 8.24$ & $14.27 \pm 2.61$ & $24.89 \pm 1.89$ \\
\hline
\end{tabular}

All subjects were investigated by a specialist, none of this is visible pathology or prior to body level or neurological musculoskeletal or orthopaedic that could change its capability to perform strength training and weightlifting.

The study population was randomly divided into two groups a control group (CG; $N=$ 15 ) and a weightlifting resistance training group (WRTG; $N=15$ ), one would follow a specific plan consisting of weightlifting exercises. The training lasted 6 weeks with 3 sessions per week.

\subsection{Testing Procedures}

After a month, all the players have completed a familiarization phase at different testing procedures. A progress of strength and power of the lower limbs (maximum-1RM strength $1 / 2$ squat, sprint $(10 \mathrm{~m})$, squat jump and countermovement jump) and upper limbs (hand-grip, throwing medicine ball, 1-RM bench press) during which they were coached for correct technical execution of exercises.

The batteries of tests were performed by the same examiners before and after six weeks of training (physical trainers and national coaches). The battery of tests includes anthropometric estimation (standing height, body mass, body mass index (BMI) and a percentage of body fat), all tests were charged at the team's training national table tennis hall at the youth city el Menzah, Tunis.

The two groups (WRTG and CG) were tested before and after the six-week training period for all dependent variables. Each evaluation was performed on four different days with the same progression of tests. The tests were performed at the same time of day in order to limit the effect of chronobiology. The Participants were asked to wear the same clothes and shoes and to refrain from any laborious or exhausting training in the previous twenty-four hours. For each test, all subjects were verbally encouraged to perform all tests with full ability. Ten minutes of standard warm-up including a moderate speed race followed by some dynamic stretching exercises and specific exercises prior to each session.

The following measures were implemented: standing height, body mass and the four skin folds (biceps, triceps, sub-scapular and supra-iliac). All measures were taken by the same examiner in conformity with the positions and techniques recommended by the International Biological Program.

\section{Maximal strength $1 / 2$ squat $(\mathrm{kg})$ Maximal strength Bench press $(\mathrm{kg})$}

The $1 \mathrm{RM}$ was then determined for each participant for the squat and bench press. Each participant performed the following: 1) 8 - 10 repetitions at approximately $50 \%$ of $1 \mathrm{RM}$; 2) 1 minute of rest and then 3 - 5 repetitions at approximately $75 \%$ of $1 \mathrm{RM}$; 3 ) 2 - 
3 minutes of rest and then 3 - 4 attempts at $1 \mathrm{RM}$ with 2-minute rest between attempts. After each attempt, the weight was increased by $1-10 \mathrm{~kg}$ until failure. The final weight lifted was the $1 \mathrm{RM}$.

For the bench press, participants were required to keep their back on the bench and feet on the floor during the entire test. Assistance was provided in lifting the bar from the rack. Participants then held the bar briefly, unassisted, with straight arms until a signal was given to lower the bar to the chest. With the bar motionless on the chest, a second signal was given to press the bar to full elbow extension.

The squat test was performed using a power rack placed just below $90^{\circ}$ of hip flexion for safety. The participant lowered the bar with neutral spine with the bar resting on the trapezius muscle. The descent stopped when the hamstring muscles were parallel with the floor. A raband was tied to the squat rack at the desired squat depth. After reaching the appropriate depth, the participant raised the weight to full knee and hip extension.

\section{Maximal strength hand grip $(\mathrm{kg})$}

The dynamometer was determined on a calibrated with visual feedback (Harpenden Dynamometer, British Indicators, Ltd., UK) and adjusted to each subject's hand using the dominant hand used for data analysis. The best of three maximal trials with 1-min recovery in between was used for analysis.

\section{Vertical Jump (cm)}

Vertical jump height was assessed using a portable platform (Quattro-Jump; Kisler, Winterthur, Switzerland) according to the procedure described by (Chaouachi et al., 2011). Participants were instructed to keep their hands on their hips to minimize lateral and horizontal displacement during performance, to prevent any influence of arm movements on the vertical jumps, and to avoid coordination as a confounding variable in the assessment of the leg extensors' neuromuscular performance. Participants were encouraged to perform the eccentric phase of the jump as quickly as possible to maximize jump height. Three trials were performed with approximately 2 minutes recovery, and the best result was used for analysis.

\section{Performance Sprint $5 \mathrm{~m}(s)$}

Infrared photoelectric cells with polarizing filters and a handheld computer were used to measure sprint times to 1/100th of a second (Brower Timing Systems, Salt Lake City, Utah, États-Unis) and were placed at the start and at $5 \mathrm{~m}$. The starting position was standardized for all participants. They started in a standing position (split stance) with the toe of the preferred foot forward $0.3 \mathrm{~m}$ behind the starting gate. This was intended to allow some forward lean and cause triggering of the timing system as soon as the subject moved. The photocells were set approximately $0.5 \mathrm{~m}$ above the floor, which was typically around hip level to capture the trunk movement rather than a false trigger from a limb. The participants were not permitted to use a "rolling" start, to eliminate momentum, and were instructed to sprint with maximum effort when they were ready. All sprints were performed with running shoes on a hard surface outside.

\section{Performance sprint/agility $(s)$}

The total distance of the test sprint/agility is $29-\mathrm{m}$. Infrared photoelectric cells with 
polarizing filters and a handheld computer were used to measure sprint times to 1/100th of a second (Brower Timing Systems, Salt Lake City, Utah, États-Unis) and were placed at the start 1 is triggered to the first leg movement. The player must complete the course. The player starts running before the red line in the axis of the cone 1 (yellow line). The Infrared photoelectric cells are activated in the first movement of foot. Departure of cone 1 sidestepped and to come to stop in 2 by watching the inside of the course, to touch the cone 2 and to return their sidestepped in cone 1 around 1, the same thing of cone 1 to cone 3 then going of cone 1 to cone 4 to running before to touch the cone and return there running defers up to the red line (international table tennis Federation).

\section{Performance throwing medicine Ball ( $m$ )}

Participants were instructed to stand with their feet at shoulders width, side on to the intended direction of the throw. Participants held a 3-kg medicine ball with straight arms facing the direction opposite to the intended direction of the throw. Although maintaining straight arms, participants then rotated their upper and lower body through $180^{\circ}$ before releasing the medicine ball with maximal velocity toward the intended target. Three attempts were given with 1 minute of rest between each throw. The greatest distance was recorded for further analysis [International Table Tennis Federation].

\section{Training Program}

The training program was conducted over a period of six weeks with three weekly sessions spaced at least 48 hours. A training mesocycle makes a total of 18 sessions training. Prior to beginning the weightlifting resistance training program, participants performed one-repetition maximum (1 RM) tests for the program in accordance with NSCA guidelines (Baechle et al., 2008). Each training session consisted of three exercises designed for lower and upper limbs with 2 - 4 sets and $4-8$ reps, and a recovery time of three minutes inter-series and five minutes inter-exercises. The resistance weightlifting program contains power snatch, power clean and squats with two assistance exercises that are push press and jerk from rack.

At the beginning of each training session, subjects start training with a dynamic warm-up for $20 \mathrm{~min}$ followed by static stretching exercises. The increase in expenses was ensured by increasing week by week the training load (resistance $\mathrm{x}$ number of sets $\mathrm{x}$ reps). In the last week of mesocycle, the load was reduced to ensure adaptations and taper.

Particular attention was paid to the technical execution especially for the Olympic exercises especially power snatch that demand speed and highly technical. Particular attention was paid to the technical execution especially for the Olympic exercises especially power snatch that demand speed and highly technical execution and are given mainly instructions and feedback for placement back at the start.

The weight training program for weightlifting resistance training group was planned over six weeks in the competitive phase of the season. With a frequency of three weekly 
sessions performed every Monday, Wednesday and Friday, immediately after the warm up. Our study was conducted between the 26th and the 33rd week of the season, after the second preparatory period.

All the manipulations took place in the city of youth training hall of Tunis. A two week before the start of the study, the subjects participated in an orientation phase. During which they were coached for correct technical execution of training exercises.

The different experimental protocols were applied to several days a randomized manner. Experienced observers were present to ensure the safety of subjects and to ensure proper technical execution of training exercises with additional loads. The participants refrained from making too intense activity, weight training and this, at least 48 hours before the beginning of each experimental session. Instructions were given to subjects before the start of manipulation to minimize external factors in conflict (related to sleep or food for example).

The night before each experimental session, he was asked subjects to maintain a fixed hour of sleep (at least sleep) and a usual diet. During the period of experiments, subjects had been banned from using stimulants (e.g. Caffeine) or alcohol may increase or compromise their wakefulness. Moreover, he was asked to maintain their usual physical activities and avoid any strenuous activity the day before and during the course of the study. Adequate hydration was allowed to athletes during experimental sessions to avoid the risk of dehydration. Experienced observers were present to ensure the safety of subjects and to ensure proper technical execution strength exercises.

Each training session included the excursions exercises for the extensor muscles of the upper and lower limbs (front squat, back squat, power snatch, power clean, push jerk and jerk from rack). The technical gesture 1/2 Squat was chosen to measure the 1-RM staff of all participants. The control group followed a regular training without resistance training. All subjects performed the first tests before training and the second.

\section{Statistical Analyses}

Data are presented as mean and standard deviation. We used the comparison of statistical tools such as the means and variances for the two samples. Student test is a variance analysis tool 2 factors was used. To compare the effects of training with weightlifting resistance training group, a mixed design was established (time factor for testing: pre-post: repeated measurements) $\times 2$ (groups of factors: weightlifting resistance training and control). In addition, an analysis of variance in a factor with repeated measures was performed for each group to show changes pre and post-test in each group. We accepted $p \leq 0.05$ as a criterion for statistical significance. The statistical treatment was performed using the computer software (SPSS 21) operating on PC.

\section{Results}

A six weeks of training muscle strength which is based on weightlifting exercises results showed a significant improvement in 1-RM of maximum strength lower and upper limbs (respectively $p<0.05 ; 7.87 \mathrm{~kg}$ or $8.29 \%$ and $p<0.04 ;+10.7 \mathrm{~kg}$ or $17.75 \%$ Table 
2). Besides, this raise has been followed by significant changes in muscle strength of the hand at the WRTG compared to CG ( $p<0.01 ; 4.6 \mathrm{~kg}$ or $13.54 \%$ progress in Table 2 ).

Performance heights SJ and CMJ increased as well in the WRTG corresponding to CG $(p<0.05$ and respectively $p<0.01)$ (Table 2$)$. The progress proportion is in the order of $+10.99 \%$ for the SJ and $+8.05 \%$ for the CMJ (or $2.67 \mathrm{~cm}$ for SJ and $2.95 \mathrm{~cm}$ for the CMJ).

The enhancement of the maximum strength of the lower limbs was followed by a significant progress in sprint speed performance on $5 \mathrm{~m}$ distance and agility/speed (respectively $p<0.05$ and $p<0.01$ ) (Table 3 ). The post-training performance achievement is of the order of $-3.23 \%$ for sprint speed of $5 \mathrm{~m}$ and $-2.42 \%$ for agility/speed (or -0.04 $\mathrm{s}$ to $5 \mathrm{~m}$ speed and race $-0.51 \mathrm{~s}$ for agility/speed).

There was also a significant achievement in the performance of throwing medicine ball for WRTG compared to CG (Table 3). The progress proportion is in the order of $4.44 \%$ for throwing medicine ball ( $24 \mathrm{~cm}$ for throwing medicine ball).

Table 2. Pre- and post-test results for maximal strength lower and upper limbs and vertical jump performance for training group (WRTG) and control group (CG) (mean $\pm \mathrm{SD}$ ).

\begin{tabular}{|c|c|c|c|}
\hline & Test & WRTG $(n=15)$ & CG $(n=15)$ \\
\hline \multirow{2}{*}{ Maximal strength $1 / 2$ squat $(\mathrm{kg})$} & Pre & $93.93 \pm 9.19$ & $94.20 \pm 4.29$ \\
\hline & Post & $102.47 \pm 11.39^{* * \#}$ & $91.27 \pm 4.09^{* *}$ \\
\hline \multirow{2}{*}{ Maximal strength bench press $(\mathrm{kg})$} & Pre & $57.20 \pm 13.21$ & $58.27 \pm 11.71$ \\
\hline & Post & $67.27 \pm 15.08^{* *} \#$ & $54.67 \pm 11.46^{* *}$ \\
\hline \multirow{2}{*}{ Maximal strength hand grip $(\mathrm{kg})$} & Pre & $34.25 \pm 3.05$ & $33.69 \pm 2.23$ \\
\hline & Post & $38.89 \pm 3.38^{\star * \# \#}$ & $32.23 \pm 2.21^{\star *}$ \\
\hline \multirow{2}{*}{ Counter movement jump $(\mathrm{cm})$} & Pre & $36.7 \pm 5.06$ & $33.18 \pm 5.62$ \\
\hline & Post & $39.66 \pm 5.31^{\star \star \#}$ & $32.76 \pm 5.49^{\star \star}$ \\
\hline \multirow{2}{*}{ Squat jump (cm) } & Pre & $24.33 \pm 2.61$ & $24.35 \pm 3.27$ \\
\hline & Post & $27.01 \pm 2.82^{\star * \# \#}$ & $23.95 \pm 3.33^{* *}$ \\
\hline
\end{tabular}

${ }^{*} p<0.05$ for pre- and post-tests within-group change in performance. $\# p<0.05$ for pre- and post-tests betweengroup change in performance.

Table 3. Pre- and post-test results for sprint, sprint agility and throwing medicine Ball performance for training group (WRTG) and control group (CG) (mean $\pm \mathrm{SD}$ ).

\begin{tabular}{cccc}
\hline & Test & WRTG (n=15) & CG (n= 15) \\
\hline Performance sprint $5 \mathrm{~m}(\mathrm{~s})$ & Pre & $1.19 \pm 0.11$ & $1.15 \pm 0.08$ \\
Performance sprint/agility (s) & Post & $1.15 \pm 0.11 \#$ & $1.19 \pm 0.08^{* *}$ \\
& Pre & $20.87 \pm 0.74$ & $22.25 \pm 0.66$ \\
Performance throwing medicine ball $(\mathrm{m})$ & Post & $20.36 \pm 0.80 \# \#$ & $22.97 \pm 0.86^{* *}$ \\
& Pre & $5.44 \pm 0.38$ & $4.90 \pm 0.2$ \\
& Post & $5.68 \pm 0.39^{* * \# \#}$ & $4.85 \pm 0.2^{* *}$ \\
\hline
\end{tabular}

${ }^{*} p<0.05$ for pre- and post-tests within-group change in performance. $\# p<0.05$ for pre- and post-tests betweengroup change in performance. 


\section{Discussion}

The reason of this analysis is to explore the responses of the different dynamic muscle strength with diverse and intense weightlifting exercises $(70 \%-85 \%$ of $1-\mathrm{RM})$, on the performance of the maximum strength of the lower limbs, higher, vertical jump, the performance of sprints and agility. The outcomes of this work have shown that due to this type of strength training we can suggest that the increase of maximum strength of the lower limbs $(+9.08 \% ; p<0.05)$ was followed by an improving the heights of CMJ $(8.05 \%, p<0.01)$.

The performance of sprint 5 meters $(-3.23 \%, p<0.05)$ and agility performance $(-2.42 \% ; p<0.01)$ post training compared to CG. At the same time, there were also a very important and significant performance gains in muscle strength of upper members for throwing medicine ball $(4.44 \% ; p<0.01)$ and the maximal strength hand grip (13.53; $p<0.01)$ in the post training WRTG compared to CG.

\section{The performance of muscular strength}

Until now, the assumptions about the advantages of coordinating strength training with weightlifting exercises on performance in table tennis players remain unknown. Maybe, there isn't a muscle building program in certain duration that lead to the performance gains of maximum strength, vertical jump, sprint and agility in table tennis (Fernandez-Fernandez et al., 2015).

Several previous works in racket sports (Tennis, Squash...) used moderate weight loads (50\% - 65\% 1-RM) (Sannicandro et al., 2014; Fernandez-Fernandez et al., 2015; Sarabia et al., 2015; Pialoux et al., 2015). None the less, different results have been reported by the work that investigated the effect of the unification of resistance programs with low to moderate loads on athletic performance (Sannicandro et al., 2014; Pialoux et al., 2015).

However, the work efficiency of high intensity physical exercises with heavy loads when reforming muscle performance is really rare (Pialoux et al., 2015). Yet, in our work we see a significant progress in maximum strength of the lower limbs measured by the $1 / 2$ squat exercises, medicine ball throwing, strength hand grip and the bench press in the WRTG compared to CG.

Actually, short-term training programs (6 to 8 weeks) coordinated in the season is favoured by researchers, because the progressive overload involved in most cases a likely the development in the quality of the force (Kraemer et al., 2002; Behm, 2005; Crewther et al., 2005; Kraemer et al., 2009). Most of our conclusions are rational with some studies in this field since training with $1-\mathrm{RM} 1 / 2$ squat around $60 \%$ to $80 \%$ was followed by changes in muscle strength upper and lower limbs (Kraemer et al., 2002; Kraemer et al., 2009; Sannicandro et al., 2014; Pialoux et al., 2015).

The Specific studies have shown that muscle strength can be stronger when the eccentric strengthening protocols are used in the resistance training program (Cormie et al., 2007; Cormie et al., 2011).

Thus, Fernandez-Fernandez et al. (2015) displayed that short-term training of the dynamic strength (i.e., tennis) can lead to an increase in muscle strength up to $10 \%$ 
progress.

This demonstrates that the coordination of dynamic muscle strength with intensity (70\% - 80\% of 1-RM) high during the competitive phase should be of outstanding importance for table tennis coaches looking to develop the performance of the strength of their players.

After all, the process of such model of dynamic strength (with weightlifting exercises) must take into consideration the intensity of training loads (Cormie et al., 2011; Crewther et al., 2011).

\section{The performance of the vertical jump}

Not only the muscle strength of the lower limbs has merged, but the vertical jump performance for fashion as well CMJ jumps in WRTG compared to CG $(+8.05 \% p<$ 0.05 ) because of the training squat (front and Back) and two Olympic lifts.

In fact, several studies have reported a rise in vertical jump performance which can be achieved by strength exercises at higher training intensities ( $>80 \%$ of 1 -RM) (Cormie et al., 2007).

Helgerud et al. (2002), used 8 weeks of strength training in elite soccer players at 2 sessions per week, 4 sets of 4 reps with a load of $90 \%$ of 1 -RM, in concentric pattern, players developed their CMJ $+6.8 \%$.

Saez de Villarreal et al. (2013), performing the same type of study (exercises: Squats and muscle action) measured the percentage incomes in vertical jump around $7 \%$ at $p<$ 0.05 in the WRTG compared to CG.

In contrast to these results, other studies have displayed that there is no progress in the performance of vertical jump after weight training programs conducted at intensity's ranging from 40\% - 65\% of 1-RM (Saez Saez de Villarreal et al., 2007; Struzik \& Zawadzki, 2013; Crewther et al., 2011).

We can say that the percentage gain of the CMJ and SJ performance in our study was of the order of $+8.05 \%$ post training, these statistics are similar to those reported by (Markovic et al., 2007; de Villarreal et al., 2009).

So, jumping exercises are advocated as a suitable approach for demanding sports explosiveness and develop vertical jump including table tennis (Zagatto et al., 2008; Malagoli Lanzoni et al., 2014; Munivrana et al., 2015).

\section{The performance of the speed}

The conclusions focus on the training protocol explosive force as proposed here even develops sprint speed performance on distance of $5 \mathrm{~m}$. Actually, the programs based on dynamic exercises (weightlifting exercise) mostly used to rise the neuromuscular rigidity (Kraemer et al., 2002; Kraemer et al., 2009) and this characteristic makes it possible to develop sprint speed (Kraemer et al., 2002; Kraemer et al., 2009).

The outcomes of our study revealed a progress in the statistics with a gain of $3.23 \%$ at $p<0.05$ for the performance in the $5 \mathrm{~m}$ WRTG compared to CG. It is not easy to draw a concrete explanation to compare our results with the studies reported in this realm, it's well known that now there's no studies that addressed the effect of strength training explosive performance speed of the elite table tennis players. 
We can admit that sprinting performance gain over $5 \mathrm{~m}$ distance could be attributed to the progress of the explosive force created when the muscle contracts after stretching (Häkkinen et al., 2003; Herrero et al., 2006).

Besides, during intense training and explosive, muscles can be shortened to generate power and to develop mechanical work (Häkkinen et al., 2003). They produce strength in association with tendons to store and recover energy from the elastic tension (Saez de Villarreal et al., 2013).

\section{The performance of agilitylspeed}

Agility is one of the predictive variables of physical performance at the elite table tennis players (Kondrič et al., 2013; Martin et al., 2015). The studies of the outcomes of the WRTG post training shows a significant difference $(p<0.01)$ for a narrow progress of about $+2.42 \%$ is recorded in the WRTG after explosives training six weeks.

In the high-level sport, agility performance is one of the constituent of athletic performance that needs a favourable maintenance and a good choice of exercises in the training program (Young et al., 2014; Paul et al., 2016).

Our outcomes certify the potency of the resistance training program which is based on the weightlifting exercises. Other studies on more homogenous study populations and a larger size would be even more interesting if we want to achieve optimum results.

\section{Conclusion}

Our analysis displayed that driving the explosive force based on the weightlifting exercises $(70 \%-85 \%$ of $1-\mathrm{RM})$ applied at the elite table tennis players for 6 weeks with three weekly sessions enabled a progress in of maximum strength, vertical jump, sprint performance and agility

The training used in this study is an active training approach that promotes the stretch-shortening cycle at the musculature of the upper and lower limbs involving a concentric contraction after a fast and powerful eccentric contraction. This develops the athletic performance of our table tennis players.

Our evidences display not only increased production of muscle strength (maximum strength of $1 / 2$ squat, bench press, throwing medicine ball), but also gain the vertical jump (SJ and CMJ) sprint performance (10-m). It demonstrates that it is important to incorporate an appropriate weight training program in table tennis player's elites in the season.

Developing the physical performance shown in this study reveals great a practical interest for table tennis coaches, because the performance in the sport depends on the specific power, jumping, sprinting and agility.

They should deal with adding a table tennis training to develop muscle strength of upper and lower limbs of their athletes as it appears that the benefits of this method are higher than those of traditional approaches of strength training.

They would be important to integrate the consequences of the additional costs and contrasting low to moderate intensity's including dynamic stimulation that could be more beneficial to the explosive performance for lower limbs than conventional ap- 
proaches for high-level table tennis players.

This could be used and tested on populations of table tennis players of different ages and sexes to determine if developed explosive force would be due to muscle or nervous adaptation.

\section{Acknowledgements}

The authors express their gratitude to Mr. Ramzi Belhadj Mabrouk the technical director of Tunisian tennis table federation and all the subjects for their cooperation.

\section{References}

Baechle, T. R., Earle, R. W., and National Strength \& Conditioning Association (US) (2008). Essentials of Strength Training and Conditioning. Champaign, IL: Human Kinetics.

Behm, D. G. (2005). Neuromuscular Implications and Applications of Resistance Training. The Journal of Strength \& Conditioning Research, 9, 264-274. http://dx.doi.org/10.1139/h11-079

Chaouachi, A., Poulos, N., Abed, F., Turki, O., Brughelli, M., Chamari, K., Drinkwater, E. J., \& Behm, D. G. (2011). Volume, Intensity, and Timing of Muscle Power Potentiation Are Variable. Applied Physiology, Nutrition, and Metabolism, 36, 736-747.

Cormie, P., McCaulley, G. O., Triplett, N. T., \& McBride, J. M. (2007). Optimal Loading for Maximal Power Output during Lower-Body Resistance Exercises. Medicine \& Science in Sports \& Exercise, 39, 340-349. http://dx.doi.org/10.1249/01.mss.0000246993.71599.bf

Cormie, P., McGuigan, M. R., \& Newton, R. U. (2011). Developing Maximal Neuromuscular Power: Part 2-Training Considerations for Improving Maximal Power Production. Sports Medicine, 41, 125-146. http://dx.doi.org/10.2165/11538500-000000000-00000

Crewther, B. T., Kilduff, L. P., Cunningham, D. J., Cook, C., Owen, N., \& Yang, G. Z. (2011). Validating Two Systems for Estimating Force and Power. International Journal of Sports Medicine, 32, 254-258. http://dx.doi.org/10.1055/s-0030-1270487

Crewther, B., Cronin, J., \& Keogh, J. (2005). Possible Stimuli for Strength and Power Adaptation: Acute Mechanical Responses. Sports Medicine, 35, 967-989. http://dx.doi.org/10.2165/00007256-200535110-00004

de Villarreal, E. S., Kellis, E., Kraemer, W. J., \& Izquierdo, M. (2009). Determining Variables of Plyometric Training for Improving Vertical Jump Height Performance: A Meta-Analysis. The Journal of Strength \& Conditioning Research, 23, 495-506. http://dx.doi.org/10.1519/JSC.0b013e318196b7c6

Fédération International de Tennis de Table. http://www.ittf.com/

Fernandez-Fernandez, J., Sanz-Rivas, D., Saes de Villarreal, E., \& Moya, M. (2015). The Effects of 8-Week Plyometric Training on Physical Performance in Young Tennis Players. Pediatric EXercise Science, 28, 77-86. http://dx.doi.org/10.1123/pes.2015-0019

Häkkinen, K., Alen, M., Kraemer, W. J., Gorostiaga, E., Izquierdo, M., Rusko, H., Mikkola, J., Häkkinen, A., Valkeinen, H., Kaarakainen, E., Romu, S., Erola, V., Ahtiainen, J., \& Paavolainen, L. (2003). Neuromuscular Adaptations during Concurrent Strength and Endurance Training versus Strength Training. European Journal of Applied Physiology, 89, 42-52.

Helgerud, J., Kemi, O. J., \& Hoff, J. (2002). Pre-Season Concurrent Strength and Endurance Development in Elite Soccer Players. In J. Hoff, \& J. Helgerud (Eds.), Football (Soccer): New Developments in Physical Training Research (pp. 55-66). Trondheim: NTNU.

Herrero, J. A., Izquierdo, M., Maffiuletti, N. A. et al. (2006). Electrostimulation and Plyometric 
Training Effects on Jumping and Sprint Time. International Journal of Sports Medicine, 27, 533-539.

Kondrič, M., Zagatto, A. M., \& Sekulić, D. (2013). The Physiological Demands of Table Tennis: A Review. Journal of Sports Science and Medicine, 12, 362-370.

Kraemer, W. J., \& Ratamess, N. A. (2004). Fundamentals of Resistance Training: Progression and Exercise Prescription. Medicine \& Science in Sports \& Exercise, 36, 674-688.

Kraemer, W. J., Adams, K., Cafarelli, E., Dudley, G. A., Dooly, C., Feigenbaum, M. S., Fleck, S. J., Franklin, B., Fry, A. C., Hoffman, J. R., Newton, R. U., Potteiger, J., Stone, M. H., Ratamess, N. A., \& Triplett-McBride, T. (2002). American College of Sports Medicine. Progression Models in Resistance Training for Healthy Adults. Medicine \& Science in Sports \& Exercise, 34, 364380. http://dx.doi.org/10.1097/00005768-200202000-00027

Kraemer, W. J., Adams, K., Cafarelli, E., Dudley, G. A., Dooly, C., Feigenbaum, M. S., Fleck, S. J., Franklin, B., Fry, A. C., Hoffman, J. R., Newton, R. U., Potteiger, J., Stone, M. H., Ratamess, N. A., \& Triplett-McBride, T., American College of Sports Medicine Position Stand (2009). Progression Models in Resistance Training for Healthy Adults. Medicine \& Science in Sports \& Exercise, 41, 687-708. http://dx.doi.org/10.1249/MSS.0b013e3181915670

Malagoli Lanzoni, I., Di Michele, R., \& Merni, F. (2014). A Notational Analysis of Shot Characteristics in Top-Level Table Tennis Players. European Journal of Sport Science, 14, 309-317. http://dx.doi.org/10.1080/17461391.2013.819382

Markovic, G., Jukic, I., Milanovic, D., \& Metikos, D. (2007). Effects of Sprint and Plyometric Training on Muscle Function and Athletic Performance. The Journal of Strength \& Conditioning Research, 21, 543-549.

Martin, C., Favier-Ambrosini, B., Mousset, K., Brault, S., Zouhal, H., \& Prioux, J. (2015). Influence of Playing Style on the Physiological Responses of Offensive Players in Table Tennis. The Journal of Sports Medicine and Physical Fitness, 55, 1517-1523.

McBride, J. M., Triplett-McBride, T., Davie, A., \& Newton, R. U. (1999). A Comparison of Strength and Power Characteristics between Power Lifters, Olympic Lifters, and Sprinters. Journal of Strength \& Conditioning Research, 13, 58-66. http://dx.doi.org/10.1519/00124278-199902000-00011

Munivrana, G., Petrinović, L. Z., \& Kondrič, M. (2015). Structural Analysis of Technical-Tactical Elements in Table Tennis and Their Role in Different Playing Zones. Journal of Human Kinetics, 47, 197-214. http://dx.doi.org/10.1515/hukin-2015-0076

Paul, D. J., Gabbett, T. J., \& Nassis, G. P. (2016). Agility in Team Sports: Testing, Training and Factors Affecting Performance. Sports Medicine, 46, 421-442.

Pialoux, V., Genevois, C., Capoen, A., Forbes, S. C., Thomas, J., \& Rogowski, I. (2015). Playing vs. Nonplaying Aerobic Training in Tennis: Physiological and Performance Outcomes. PLoS ONE, 10, e0122718. http://dx.doi.org/10.1371/journal.pone.0122718

Saez de Villarreal, E., Requena, B., Izquierdo, M., \& Gonzalez-Badillo, J. J. (2013). Enhancing Sprint and Strength Performance: Combined versus Maximal Power, Traditional Heavy-Resistance and Plyometric Training. Journal of Science and Medicine in Sport Home, 16, 146150. http://dx.doi.org/10.1016/j.jsams.2012.05.007

Saez Saez de Villarreal, E., González-Badillo, J. J., \& Izquierdo, M. (2007). Optimal Warm-Up Stimuli of Muscle Activation to Enhance Short and Long-Term Acute Jumping Performance.

European Journal of Applied Physiology, 100, 393-401. http://dx.doi.org/10.1007/s00421-007-0440-9

Sannicandro, I., Cofano, G., Rosa, R. A., \& Piccinno, A. (2014). Balance Training Exercises Decrease Lower-Limb Strength Asymmetry in Young Tennis Players. Journal of Sports Science 
and Medicine, 13, 397-402.

Sarabia, J. M., Fernandez-Fernandez, J., Juan-Recio, C., Hernández-Davó, H., \& Urbán, T., Moya, M. (2015). Mechanical, Hormonal and Psychological Effects of a Non-Failure Short-Term Strength Training Program in Young Tennis Players. Journal of Human Kinetics, 45, 81-91. http://dx.doi.org/10.1515/hukin-2015-0009

Struzik, A., \& Zawadzki, J. (2013). Leg Stiffness during Phases of Countermovement and Take-Off in Vertical Jump. Acta of Bioengineering and Biomechanics, 15, 113-118.

Toriola, A. L., Toriola, O. M., \& Igbokwe, N. U. (2004). Validity of Specific Motor Skills in Predicting Table-Tennis Performance in Novice Players. Perceptual \& Motor Skills, 98, 584-586. http://dx.doi.org/10.2466/pms.98.2.584-586

West, D. J., Owen, N. J., Cunningham, D. J., Cook, C. J., \& Kilduff, L. P. (2011). Strength and Power Predictors of Swimming Starts in International Sprint Swimmers. Journal of Strength \& Conditioning Research, 25, 950-955. http://dx.doi.org/10.1519/JSC.0b013e3181c8656f

West, D., Cunningham, D., Bevan, H., Crewther, B., Cook, C., \& Kilduff, L. (2013). Influence of Active Recovery on Professional Rugby Union Player's Ability to Harness Postactivation Potentiation. The Journal of Sports Medicine and Physical Fitness, 53, 203-208.

Yáñez Sepúlveda, R., Barraza, F., Rosales Soto, G., Báez, E., \& Tuesta, M. (2015). [Anthropometric Chilean Table Tennis Players of Competitive Features]. Nutrición Hospitalaria, 32, 16891694.

Young, W., \& Rogers, N. (2014). Effects of Small Sided Game and Change of Direction Training on Reactive Agility and Change of Direction Speed. Journal of Sports Sciences, 32, 307-314. http://dx.doi.org/10.1080/02640414.2013.823230

Zagatto, A. M., Papoti, M., \& Gobatto, C. A. (2008). Anaerobic Capacity May Not Be Determined by Critical Power Model in Elite Table Tennis Players. Journal of Sports Science \& Medicine, 7 , 54-59.

Submit or recommend next manuscript to SCIRP and we will provide best service for you:

Accepting pre-submission inquiries through Email, Facebook, LinkedIn, Twitter, etc.

A wide selection of journals (inclusive of 9 subjects, more than 200 journals)

Providing 24-hour high-quality service

User-friendly online submission system

Fair and swift peer-review system

Efficient typesetting and proofreading procedure

Display of the result of downloads and visits, as well as the number of cited articles

Maximum dissemination of your research work

Submit your manuscript at: http://papersubmission.scirp.org/

Or contact ape@scirp.org 